\title{
Fragmentation in Production, Vertical Integration and Wage Inequality: A Theoretical Note*
}

\author{
Gouranga G. Das \\ Department of Economics, Hanyang University Erica Campus, Ansan, South Korea \\ Email: dasgouranga@gmail.com
}

Received November 7, 2012; revised December 8, 2012; accepted December 15, 2012

\begin{abstract}
Developing a three-sector and four-factor general equilibrium model, this paper offers an explanation of wage inequality in a vertically fragmented production structure typical of off-shore outsourcing to developing countries like China or India. The model characterizes a typical developing economy where intermediate good is produced using capital and local low-skilled worker, traditional sector uses unskilled worker to produce agricultural products and skilled worker works in tandem with intermediates to produce final goods for export. The model furnishes that wage dispersion could be explained theoretically in this specific-factor general equilibrium structure where factor returns are endogenously determined within a production structure with middle products. In particular, scenario analysis shows that increase in relative price of final good aggravates wage inequality, whereas opposite happens when price of intermediates and import-competing sector inflates. Skilling the unskilled and protecting the sector intensive in low-skilled could attenuate the adverse impact.
\end{abstract}

Keywords: Wage Inequality; Fragmentation; Vertical Specialization; Specific Factor

\section{Overview and Background}

"We live in an age of outsourcing."

$$
\text { -Grossman and Helpman ([1], p. 135) }
$$

\subsection{Prelude}

A noticeable empirical phenomenon dominating the international trade literature is the evidence of wage inequality across skill categories. The issue of globalization, buoyancy in foreign trade and investment and its distributive impacts via wage dispersion has received intellectual attention. The quotation above confirms the ricochet effect of the current spate of global integration and geographical de-concentration of production, via both extensive and intensive growth in trade in products and services alike. Last few years, there has been intense debate on outsourcing and wage inequality. It is from this perspective that we contribute to the debate on tradewage nexus.

Outsourcing of intermediates (materials) and business services have become an important component of international trade along with the rising speed of globalization.

\footnotetext{
*With the usual disclaimer, I acknowledge the valuable comments and suggestions from seminar participants at the UNU-WIDER, Helsinki, Finland, and Conference participants at the Oikos International Economics Academy, at Geneva in 2011. This work was supported by the research fund of Hanyang University (HY-2009-N).
}

Typically, cost-saving objective motivates sub-contracting: hiring low-wage workers from the labor-rich developing economies. Also, fragmentation and associated competition from foreign firms could break the technological barriers. Firms with laborers suited to older techniques will lose to the firms endowed with workers having access to new technology embodied in foreign capital accrued via FDI. Thus, it will give the latter a tad more competitive advantage to attract higher wage rates. The paper at hand explores the effect of fragmentation of production process on the labor market disaggregated on the basis of skill content. However, critiques argue the relative importance of technological restructuring vis-à-vis off-shoring of semi-skilled and unskilled jobs to attractive locales such as low-wage nations like India, China, and Brazil from the developed nations behind the wage inequality phenomena $[2,3]^{1}$. Thus, as globalization has impact on labor markets through modern supply chains analytical framework would facilitate understanding of such transmission channel. This is often called "unbundling"

\footnotetext{
${ }^{1}$ Typically, industries showing marks of this kind of splintering across locations of a vertically integrated production process are those with substantial scope of technological sophistication and invention such as: electronics, data processing equipment, radio, television, textiles and apparels, and mostly services like E-commerce, medical transcription, software, BPO, backroom call centers, etc., to name a few. Even these days, tutorials for teaching mathematics or sciences are outsourced to Indian teachers from especially, USA.
} 
effects via revolution in technologies, e-commerce, and fall is transport costs. Following section briefly reviews the previous works.

\subsection{Brief Literature Review}

Empirically, [4] has found rapid growth in vertical specialization trade in manufacturing thanks to fall in trade costs $^{2}$. Drawing on [5], [6] has also measured extent of outsourcing in both services and materials in Asia and found that developing regions in India, China, South-East Asia and Latin America has registered higher percentage of trade attributed to production-sharing in hi-technology products, services, and capital goods. [7] defines outsourcing measure more generally to include broader measure of intermediate inputs- "parts and components and contract work (either subcontracting a foreign firm to manufacture wholly or, the use of foreign plants for product assembly) done by others (p. 242)". Also, it includes input purchases from foreign independent suppliers as well as foreign subsidiaries of multinationals firms. For labor market effects of such vertical trade specialization [8], mentions that extent of such impact depends on design and measurement differences as well as on data or industry level aggregation. However, [7] found that outsourcing or intermediate input trade caused $15 \%-25 \%$ rise in relative wage of non-production vis-à-vis production workers, whereas skill-biased technical change (via hi-tech office equipment, computer investment and innovation) accounted for $20 \%-35 \%$ rise in wage gap during 1970-1990 for US manufacturing. Not only that, [9] has estimated that both technical change as well as North-South trade cause wage inequality. [10] has shown in a continuum of model with intermediate goods that trade in final goods could cause relative wage to disperse especially in the presence of tariff on final product. On an empirical plane, based on an imperfect competition model [11] has offered evidences of significant effect of outsourcing on widening wage gap in Indian manufacturing sector. [12] has studied the impact of South Korean offshoring on labor market in China and found impact on wage and employment in labor market in both source and destination. Given the fact that extent of such East Asian regional production networking is still unfolding, the impact is noteworthy.

Drawing on the consensus that a middle products framework can accommodate variety in production with fragmentation and skill differentiation across labors, this paper develops a particular vertical production structure in a mixed specific-factor framework. Extension of traditional corpus of trade theory due to fragmentation of production in stages has received major attention espe-

\footnotetext{
${ }^{2}$ Ratio of value-added trade to gross trade - VAX ratio - has fallen and hence, showing rise in supply-chain fragmentation in production. (The Economist: Free Exchange-Chains of Gold, August 4, 2012).
}

cially under the aegis of globalization. Impact of outsourcing on wage structure crucially hinges on the nature or type of sectors undergoing the delocalization. In other words, manufacturing outsourcing via traded intermediate inputs is the conventional outsourcing mode whereas services outsourcing enabled by IT and associated network effects are new mode owing to SBTC. Varieties of production models have emerged with none claiming dominance. These models are variants or mixtures of generic models like the Ricardian type, Specific factors model, Heckscher-Ohlin framework. Rich array of NeoClassical production models in trade considers different theoretical structures [13-15]. Typically, the models with horizontal and vertical specialization in a productive spectrum have been used to analyze diverse phenomena [16-18]. We probe beyond the quantifiable causes to present a theoretical justification in Section 2 to shed light on fragmentation and development ${ }^{3}$. Section 3 presents results and Section 4 concludes.

\section{A General Equilibrium Model of Vertical Specialization}

Domestic firms in developed economies subcontract "non-skill-intensive" part to the foreign-host - developing countries. Consider the case of a small open less developed economy incompletely specializing in two tradable sectors requiring different inputs produced by two specific heterogeneous labor types, sector-specific capital and one intermediate-input. More specifically, exportable final good (sophisticated skill-intensive good) $X$ is produced with skilled human capital $(S)$ and one capital goods (i.e., intermediate input $-I$ ) whereas I is produced in a separate production nest with capital $(K)$ and semiskilled or relatively unskilled labor (i). Also, traditional import-competing agricultural good $(Y)$ is produced using only unskilled. A stylized vertical production structure resembling this is: where some capital goods (sourced via arms' length trade, intra-firm transactions, or FDI), and unskilled/semi-skilled labor enter into production of Steel used as an intermediate in conjunction with skilled labor to produce a final good, say Automobiles. A schematic diagram depicting such structure is given in Figure 1.

Abundance of low-skilled workers in host LDCs makes produced intermediate goods (I) cheaper than anywhere. This is non-traded (or, not directly traded due to prohibitive transport costs). Lower price of " $I$ " at host gives her a comparative advantage in final good $(X)$ production. It is a vertical productive spectrum where " $T$ " enters into final goods production only after its production in initial

\footnotetext{
${ }^{3}$ For example, relatively labor-rich nations with relatively lower wages would be the preferred location of choice for concentration of laborintensive fragments of production.
} 


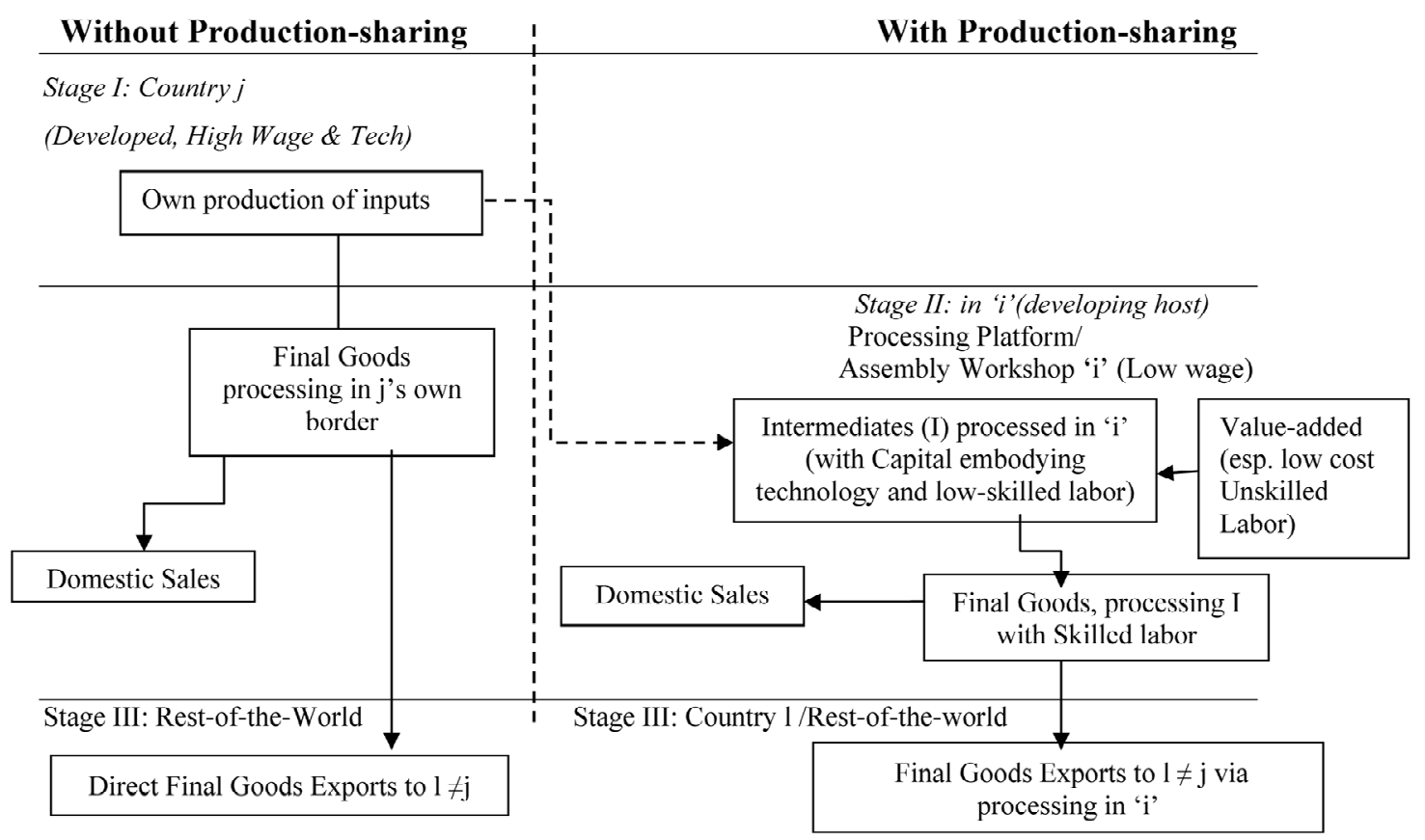

Figure 1. Schematic representation of a conceptual vertical specialization model ${ }^{4}$.

stages. By Greenfield investment or acquisition, the firm transfers some of their capital to the host so that high wage countries combine their expertise with low-wage labor for producing cheaply in the host. Examples are plenty, such as: production of i-phone (smart phones) or i-pad produced with skilled engineers and semiconductor/microchips assembled in LDCs to take advantage of abundant low-skilled workers to be used with sophisticated capital goods ${ }^{5}$. Production functions represented by (E) are assumed to exhibit linear homogeneity and diminishing returns to each type of inputs. We assume full employment of resources and perfectly competitive factor and product markets. It is assumed that perfectly flexible real wage guarantees full-employment in the economy. $X$ and $Y$ are traded, " $P$ " is non-traded and price flexibility ensures equality of domestic supply with demand. Thus,

$$
\left.\begin{array}{l}
X=X(I, S) \\
Y=Y(U) \\
I=I(K, U)
\end{array}\right\}
$$

where $X^{\prime}>0, X^{\prime \prime}<0, Y^{\prime}>0, Y^{\prime \prime}<0, I^{\prime}>0, I^{\prime \prime}<0$ with respect to respective inputs.

Following notations are used for the model:

$$
P_{j}=\text { price of the } j^{\text {th }} \text { final good } \forall j=X, Y \text {; }
$$

\footnotetext{
${ }^{4}$ Adapted from Das and Han (2013, forthcoming).

${ }^{5}$ See Feenstra and Taylor (2008) for examples. Cotton textile produced with raw cotton or IT-products and IT-enabled services produced with software, electronic ADP equipment and hardware engineer with high skill content are other examples. Purchase of state-owned plants in Eastern Europe such as Czech Republic by Western European firms.
}

$P_{I}=$ price of intermediate input, $I$.

Input-output ratios are given as below:

$a_{L}^{m}=$ amount of labor types per unit of output of $m$ sector, $\forall m \in\{X, Y, I\}, j \subset m$, and $L \in\{S, U\}$;

$a_{k}^{I}=$ amount of capital per unit of $I$;

$a_{I}^{X}=$ amount of intermediate input required to produce 1 unit of $X$;

$r=$ return to capital (given as determined in the world market);

$w_{s}, w_{u}=$ prevailing wage rate across skill categories in the economy;

$\theta_{L m}=w_{L} a_{L}^{m} / P_{m}$ is the distributive share of labor types in the production of $m$ where

$$
m \in\{X, Y, I\}, L \in\{S, U\}
$$

$\theta_{K I}=r a_{k}^{I} / P_{I}$ is the distributive share of $k^{\text {th }}$ specific capital in "I";

$\theta_{I X}=P_{I} a_{I}^{X} / P_{X}$ is the share of " $T$ " (in value terms) in $X$;

$$
\lambda_{i m}=\frac{a_{i}^{m} Q_{j}}{f_{i}}=m^{t h}
$$

commodity's input share in $i^{\text {th }}$ factor, where $Q$ is generic output and " $f$ ' is generic input types; $\sigma_{m}=$ elasticity of substitution in " $m$ " sector's production.

$\bar{K}, \bar{S}, \bar{U}$ are given endowments of capital, skilled and unskilled labor respectively.

" $\Lambda$ " = proportional changes for a variable, say $V$ such that generically

$$
\hat{V}=\frac{\mathrm{d} V}{V}
$$


Competitive equilibrium with zero pure profit condition implies that:

$$
\begin{gathered}
P_{I}=a_{K}^{I} \cdot \bar{r}+a_{u}^{I} \cdot w_{u} \\
P_{X}=a_{S}^{X} \cdot w_{S}+a_{I}^{X} \cdot P_{I}
\end{gathered}
$$

For the import-competing sector,

$$
P_{Y}=a_{u}^{Y} \cdot w_{u}
$$

Full employment conditions are:

$$
\begin{gathered}
a_{u}^{I} \cdot I+a_{u}^{Y} \cdot Y=\bar{U} \\
a_{S}^{X} \cdot X=\bar{S}
\end{gathered}
$$

We can write demand for the intermediate as:

$$
a_{I}^{X} \cdot X=I
$$

Rate of return for an LDC is globally determinedexogenously given - as are $P_{X}$ and $P_{Y}$ :

$$
r=\bar{r}
$$

Full-employment condition for capital is not needed.

Given $P_{Y}$, Equation (3), with Constant Returns to Scale, determines $w_{u}$; given $r$, then we get $P_{I}$ via (1). Once $P_{I}$ is determined, given $P_{X}$, we can solve for $w_{s}$. Using (5), we find $X$, plugging which in (6) yields $I$. From (4), by replacing $I$, we get $Y$. Equations (1)-(6) are 6 to solve for 6 variables, viz., $X, Y, I, w_{s}, w_{u}$ and $P_{I}$. The system is determinate.

Dividing (2) and (1) by (3) yields respectively:

$$
\begin{gathered}
P_{X} / P_{Y}=\frac{a_{s}^{X}}{a_{u}^{Y}} \cdot \frac{w_{s}}{w_{u}}+\frac{a_{I}^{X}}{a_{u}^{Y}} \cdot \frac{P_{I}}{P_{Y}} \\
P_{I} / P_{Y}=\frac{a_{k}^{I}}{a_{u}^{Y}} \cdot \frac{\bar{r}}{w_{u}}+\frac{a_{u}^{I}}{a_{u}^{Y}}
\end{gathered}
$$

This implies that given factor proportions and inputoutput ratio, if relative prices of final goods change in favor of $X$ (i.e., $\widehat{P_{X}}>\widehat{P_{Y}}$ ), and $P_{I}$ increases, then skillunskilled wage gap might widen. If $\widehat{P_{Y}}>\widehat{P_{I}}$, then $w_{u}$ might improve. However, following section rigorously analyzes such effects.

\section{Comparative Static Changes and Analysis}

\subsection{Equations of Change and Results}

Impact of vertically fragmented structure on wage inequality could easily be envisaged by exploiting the model's comparative static changes in the wake of price variations in the general equilibrium system. Employing Wong-Viner envelope theorem [19] and based on [13], we derive from (1)-(3) and using (7):

$$
\widehat{P_{Y}}=\theta_{u Y} \cdot \widehat{w_{u}}
$$

$\widehat{P_{I}}=\theta_{u I} \cdot \widehat{w_{u}} \quad$ (as $\theta_{K I} \cdot \hat{r}=0$, " $r$ " being fixed at world market)

$$
\widehat{P_{X}}=\theta_{s X} \cdot \widehat{w_{s}}+\theta_{I X} \cdot \widehat{P_{I}}
$$

From (11), as

$$
\begin{aligned}
\theta_{s X}+\theta_{I X}=1, \widehat{w_{s}} & =\left(\widehat{P_{X}}-\theta_{I X} \cdot \widehat{P_{I}}\right) / \theta_{s X} \Rightarrow \widehat{w_{s}}-\widehat{P_{X}} \\
& =\frac{\theta_{I X}}{\theta_{s X}}\left[\widehat{P_{X}}-\widehat{P_{I}}\right]
\end{aligned}
$$

Using (12) with (9) and (10) sequentially, we get respectively:

$$
\begin{gathered}
\widehat{w_{s}}-\widehat{w_{u}}=\frac{\widehat{P_{X}}}{\theta_{s X}}-\widehat{P_{I}}\left[\frac{\theta_{I X}}{\theta_{S X}}+\frac{1}{\theta_{u I}}\right] \\
\widehat{w_{s}}-\widehat{w_{u}}=\frac{\widehat{P_{X}}}{\theta_{s X}}-\widehat{P_{I}} \cdot \frac{\theta_{I X}}{\theta_{S X}}-\frac{\widehat{P_{Y}}}{\theta_{u Y}}
\end{gathered}
$$

In particular, consider scenarios (ceteris paribus): 1) world price of exportable increases $\widehat{P_{X}}>0, \widehat{P_{I}} \geq 0 ; 2$ ) price of importable rises such that $\widehat{P_{Y}}>0, \widehat{P_{I}} \geq 0 ; 3$ ) $\widehat{P_{X}}>\widehat{P_{Y}}>0$. Propositions below elicit the policy implications.

Proposition 1: Assuming that skilled labor is relatively important factor of production in export sector, and capital is relatively more important in intermediate good production, a one-shot increase in the relative world price of export sector causes wage inequality to deepen by reinforcing the existing wage gap.

Proof: Let $\widehat{P_{X}}>0, \widehat{P_{I}}=0$. Considering equation system (12) and (13),

$$
\widehat{w_{s}}-\widehat{w_{u}}=\frac{\widehat{P_{X}}}{\theta_{s X}}>0 \Rightarrow \widehat{w_{s}}>\widehat{w_{u}} \quad(\mathrm{QED})
$$

Let $\widehat{P_{I}}>0, \widehat{P_{X}}=(1+\gamma) \widehat{P_{I}}$ where $\gamma>0$, then

$$
\widehat{w_{s}}-\widehat{w_{u}}=\widehat{P_{I}}\left[\frac{\gamma}{\theta_{S X}}-\frac{\theta_{K I}}{\theta_{U I}}\right]>0
$$

Given

$$
\widehat{P_{I}}>0, \widehat{w_{S}}>\widehat{w_{u}} \text { iff } \frac{\gamma}{\theta_{S X}}>\frac{\theta_{K I}}{\theta_{U I}}
$$

Given relative factor-importance (intensity) assumption

$$
\theta_{K I}>\theta_{U I}, \frac{\theta_{K I}}{\theta_{U I}}>1 \Rightarrow \frac{\gamma}{\theta_{S X}}>1 \Rightarrow \gamma>\theta_{S X} \quad(\mathrm{QED}) .
$$

Thus, more than proportionate increase in world price of export sector compared to the price of intermediates and the proportion (share) of the skilled labor used with intermediate in final good production deepens wage inequality via fueling of skill demand.

Corollary 1. Output of the exportable and intermediate 
expands. Real wage of skilled workers increases.

From (12) and using $\widehat{P_{X}}=(1+\gamma) \widehat{P_{I}}$, we derive

$$
\widehat{w_{s}}-\widehat{P_{X}}=\frac{\theta_{I X}}{\theta_{s X}} \gamma \widehat{P_{I}}>0
$$

Following Jones $(1965,1971)$ and envelope theorem, we get:

$$
\sigma_{j}=\frac{\hat{a}_{i j}-\hat{a}_{h j}}{\hat{p}_{h j}-\hat{p}_{i j}}
$$

and

$$
\hat{a}_{i j}=\theta_{h j} \sigma_{j}\left(\hat{p}_{h j}-\hat{p}_{i j}\right)
$$

$\forall j \in\{X, I\}, \forall i \neq h \in\{S, U, K, I\}$ are inputs and $p_{h} \neq p_{i}$ are factor input prices.

Using (5), (6) and (17), we get

$$
\hat{X}=-\hat{a}_{S}^{X}=\theta_{I X} \sigma_{X}\left(\hat{w}_{S}-\hat{P}_{I}\right)
$$

and

$$
\hat{I}=\sigma_{X}\left(\hat{w}_{s}-\hat{P}_{I}\right)
$$

From (18) and (19), we see that $\hat{X}>0, \hat{I}>0$. As wage of skilled workers increases by more than the increase in price of exportable and that of the price of the intermediate, the real purchasing power in terms of both goods increases. However, real wage of unskilled worker falls in terms of final good, but it increases in terms of the intermediate good as with

$$
\hat{r}=0, \widehat{w_{u}}=\frac{\widehat{P_{I}}}{\theta_{u I}}>0
$$

This is because as " $T$ " is used more in the production of $X$, following price rise, as return to capital does not change, via general equilibrium adjustment wage of unskilled gain because relatively more unskilled labor work with capital at the going rate of return.

Proposition 2: Ceteris paribus, an increase in relative price of import-competing sector might improve wage inequality as wage of unskilled worker rises.

Proof: From (4), we derive:

$\lambda_{u Y} \hat{Y}+\lambda_{u I} \hat{I}=\delta_{u} \hat{w}_{u}$ where after simplification,

$$
\delta_{u}=\lambda_{u I} \theta_{k I} \sigma_{I} \text { as } \theta_{u Y}=1, \sigma_{Y}=0
$$

Hence, we simplify to get:

$$
\hat{Y}=\frac{\lambda_{u I}}{\lambda_{u Y}} \sigma_{I} \hat{w}_{u}
$$

Using (9), we get from (20a and 20b),

$$
\hat{Y}=\frac{\lambda_{u I}}{\lambda_{u Y}} \sigma_{I} \hat{P}_{Y}
$$

As $\hat{P}_{X}=0, X$ production does not alter. Thus, fol- lowing $\hat{P}_{Y}>0, \hat{Y} \geq 0$ as more unskilled labor move from $I$ - to $Y$-sector, resulting in $\hat{w}_{u}>0$. From (9) and (10), we infer that in this case $\hat{P}_{Y}>0 \Rightarrow \hat{w}_{u}>0 \Rightarrow \hat{P}_{I}>0$ Given $\hat{P}_{X}=0$, from (11), we get $\hat{w}_{s}<0$. So, wage inequality decreases.

Proposition 3: An increase in relative price of exportable compared to the relative price of import competing sector might aggravate wage inequality; however, if price of import-competing sector rises more than that in exportable sector, it might improve the wage gap, but can reduce the output of the export sector.

Proof: Using (10) and (11), we write:

$$
\begin{gathered}
\widehat{P_{X}}=\theta_{s X} \cdot \widehat{w_{s}}+\theta_{I X} \cdot \theta_{u I} \cdot \widehat{w_{u}} \\
\widehat{P_{Y}}=0 \cdot \hat{w}_{s}+\theta_{u Y} \cdot \widehat{w_{u}}
\end{gathered}
$$

Applying Cramer's rule for (9) and (22),

$$
\left(\begin{array}{cc}
\theta_{s X} & \theta_{I X} \theta_{u I} \\
0 & \theta_{u Y}
\end{array}\right)\left(\begin{array}{c}
\widehat{w_{s}} \\
\widehat{w_{u}}
\end{array}\right)=\left(\begin{array}{c}
\widehat{P_{X}} \\
\hat{P}_{Y}
\end{array}\right)
$$

Thus, we get from (23):

$$
\hat{w}_{s}=\frac{\hat{P}_{X}-\hat{P}_{Y} \theta_{I X} \theta_{u I}}{|\theta|}
$$

where

$$
|\theta|=\theta_{S X}\left(\text { as } \theta_{u Y}=1\right)
$$

and

$$
\hat{w}_{u}=\frac{\hat{P}_{Y} \theta_{S X}}{|\theta|}
$$

From (24a \& b), we infer that:

1) if $P_{X}>0, \hat{P}_{Y}=0 \Rightarrow w_{s}=\hat{P}_{X} / \theta_{s X}>0, \hat{w}_{u}=0$; and 2) if $\hat{P}_{X}=0, \hat{P}_{Y}>0 \Rightarrow \hat{w}_{s}>0, \hat{w}_{u}>0$.

In the former case, clearly wage inequality rises while in the latter case, it falls. This is because as price of importable employing only unskilled worker goes up, more unskilled worker migrates to that sector at the expense of the intermediate good sector. Thus, output in intermediates contracts, while export sector using output of I-sector might suffer from fall in production. This is obvious from Equations (18) and (19).

Corollary 2. If $P_{X}$ rises by more than $P_{Y}$, then direction of wage inequality depends on extent of rise in $P_{Y}$, proportionality factor, and relevant input shares.

From (24a \& b), simplifying,

$\hat{w}_{s}-\hat{w}_{u}=\hat{P}_{Y} \frac{\theta_{I X}}{\theta_{s X}}\left[\theta_{K I}+\frac{\mu}{\theta_{I X}}\right]$, when $\hat{P}_{X}=(1+\mu) \hat{P}_{Y}, \mu>0$.

Thus, $\hat{w}_{s}-\hat{w}_{u} \geq 0$,iff $\hat{P}_{Y} \geq 0, \mu>0$ It shows that directionality of wage gap depends on relative price changes 
between vertically integrated vis-à-vis traditional sector using unskilled labor shared with the outsourced intermediate good.

\subsection{Verbal Upshot}

Following the discussions in Section 3.1, we observe that in a general equilibrium theoretical model the recent upsurge in vertically integrated production structure and its impact through price and wage effects can be explained globalization and the great unbundling of production stages has caused delocalization via trade in intermediates and services. The model delivers valuable insights such as wage gap and income shares. The integration of emerging countries like China and India has triggered new dynamics in skilled-unskilled wage effects. Although workers in less developed economies are less skilled than developed world, emerging economies will be the major source of skilled workers with shift in economic centre of gravity of skill and frugal innovation towards Asia. With this, as proposition 1 shows rise in demand for skilled workers will worsen wage inequality. Considering Propositions I and III, this replicates the presence of a "Dutch Disease" type of effect following the exogenous shock. In this framework, we demonstrate that as Sector " $\mathrm{X}$ " (traded at exogenously fixed world market prices) booms or expands, the other traded sector and non-traded sector contracts with different impacts on traded innovative (skilled) manufacturing sector depending on share of capital. Also, even with wage flexibility the perverse effect on the distribution of income causes immiserization. In other words, expansion of vertical intra-industry trade and relocation will cause wage divergence unless innovation in higher education would help raise the supply of skilled workers. Proposition II shows that skill imbalances could be solved by concomitant rise in price in the sector using low-skilled workers exclusively. Thus, through labor-market reforms if there is an increase in demand for low-skilled workers the wage inequality will improve in favor of the unskilled. The immiserizing effects might dissipate. At the theoretical plane, other than Stolper-Samuelson theorem, fewer attempts $[3,13,14,16]$ have been made to model such impacts due to onslaught of off-shoring. Here we establish a link between wage gap and an increase in outsourcing by multinationals from developed countries. Thus, the gap is likely to shrink in the face of an anticipated rise in price of domestic import-competing sector using low-skilled workers. Therefore, the model captures the relative importance of price changes in exports, imports, and intermediates for factor returns.

\section{Conclusion and Implications}

Using a mixed specific factor production structure based on $[13,19]$ for a small open economy we have derived some results in the context of a vertical productive spectrum happening under increasing mode of outsourcing off-shore. Structure based on Hecskscher-Ohlin-Samuelson model has been used for explaining globalization and inequality. This particular structure could accommodate the phenomena of wage dispersion thanks to fragmentation in a variant model. However, by offering edifice of a developing economy structure, the paper shows that current spate of supply chain for industrialization in India and China, among others, could cause wage dispersion without supportive public policy. For example, developing better skilled workforce could be a way to reduce the wage gap existing between poor and non-poor. Not only is that, to attenuate the impact of foreign acquisition, complementary public policy to develop industry and appropriate skills necessary. Skilling the unskilled and protecting traditional sector are ways to balance the adverse effect.

\section{REFERENCES}

[1] G. M. Grossman and E. Helpman, "Outsourcing in a Global Economy," Review of Economic Studies, Vol. 72, No. 1, 2005, pp. 135-159. doi:10.1111/0034-6527.00327

[2] R. W. Jones, "Globalization and the Theory of Input Trade," MIT Press, Cambridge, 2000.

[3] R. C. Feenstra and G. Hanson, "Chapter 6. Global Production Sharing and Rising Wage Inequality: A Survey of Trade and Wages," In: E. K. Choi and R. J. Harrigan, Eds., Handbook of International Trade, Blackwell, Oxford, 2003. doi:10.1002/9780470756461.ch6

[4] B. Bridgman, "The Rise of Vertical Specialization Trade," Journal of International Economics, Vol. 86, No. 1, 2012, pp. 133-140. doi:10.1016/j.jinteco.2011.08.016

[5] M. Amiti and S.-J. Wei, "Fear of Service Outsourcing: Is It Justified?" Economic Policy, Vol. 20, No. 42, 2005, pp. 308-347.

[6] G. G. Das, "Globalization, Socio-Institutional Factors and North-South Knowledge Diffusion: Role of India and China as Southern Growth Progenitors," Technological Forecasting and Social Change, Vol. 79, No. 4, 2012, pp. 620-637. doi:10.1016/j.techfore.2011.05.013

[7] R. C. Feenstra and G. Hanson, "Globalization, Outsourcing, and Wage Inequality," American Economic Review, Vol. 86, No. 2, 1996, pp. 240-245.

[8] D. Horgos, "Labor Market Effects of International Outsourcing: How Measurement Matters," International Review of Economics and Finance, Vol. 18, No. 4, 2009, pp. 611-623. doi:10.1016/j.iref.2008.10.006

[9] N. Chusseau, M. Dumont and J. Hellier, "Explaining Rising Inequality: Skill-Biased Technical Change and NorthSouth Trade," Journal of Economic Surveys, Vol. 22, No. 3, 2008, pp. 409-457. doi:10.1111/j.1467-6419.2007.00537.x

[10] W. Polley, "Outsourcing on a Continuum of Intermediate 
Goods: Implications for Trade and Welfare," Indian Journal of Economics and Business, Vol. 3, Special Issue, 2004, pp. 89-102.

[11] S. Arora and A. Chakrabarti, "Importing Jobs? The Impact of Global Outsourcing on Wages in Indian Manufacturing," Indian Journal of Economics and Business, Vol. 3, Special Issue, 2004, pp. 137-152.

[12] G. G. Das and H. Han, "Trade in Middle Products between South Korea and China: A Survey on the Extent of Offshore Production-Sharing," In: B. Ashok, D. Jaffee and C. Kroll, Eds., The Oxford Handbook of Offshoring and Global Employment, Oxford University Press, Oxford. (Forthcoming 2013)

[13] R. W. Jones, "A Three-Factor Model in Theory, Trade and History," In: J. N. Bhagwati, et al., Eds., Trade, Balance of Payments and Growth-Essays in Honor of Charles P. Kindleberger, North-Holland, Amsterdam, 1971, p. 532.

[14] G. G. Das, "A Hybrid Production Structure in Trade: Theory and Implications," International Review of Economics, Vol. 56, No. 4, 2009, pp. 359-375. doi:10.1007/s12232-009-0082-9

[15] K. K. Sanyal and R. W. Jones, "The Theory of Trade in Middle Products," American Economic Review, Vol. 72, No. 1, 1982, pp. 16-31.

[16] S. Marjit and R. Acharyya, "International Trade, Wage Inequality and the Developing Economy: A General Equilibrium Approach," Physica-Verlag, Springer, Heidelberg, 2003. doi:10.1007/978-3-642-57422-1

[17] D. Hummels, J. Ishii and K.-M. Yi, "The Nature and Growth of Vertical Specialization in World Trade," Journal of International Economics, Vol. 54, No. 1, 2001, pp. 75-96. doi:10.1016/S0022-1996(00)00093-3

[18] R. W. Jones and S. Marjit, "Competitive Trade Models and Real World Features," Economic Theory, Vol. 41, No. 1, 2009, pp. 163-174. doi:10.1007/s00199-008-0394-0

[19] R. W. Jones, "The Structure of Simple General Equilibrium Models," Journal of Political Economy, Vol. 73, No. 6, 1965, pp. 557-572. doi:10.1086/259084 